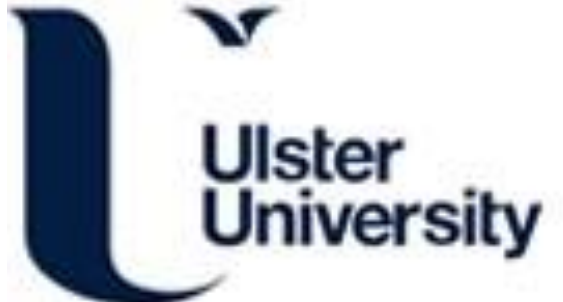

\section{Affective educational games and the evolving teaching experience}

Munoz, K., McKevitt, P., Lunney, T., Noguez, J., \& Neri, L. (2011). Affective educational games and the evolving teaching experience. In MM. Cruz-Cunha, VH. Costa Carvalho, \& PC. Almeida Tavares (Eds.), Computer games as educational and management tools: uses and approaches (pp. 206-228). IGI Global. https://doi.org/10.4018/978-1-60960-569-8.ch013

Link to publication record in Ulster University Research Portal

\section{Published in:}

Computer games as educational and management tools: uses and approaches

\section{Publication Status:}

Published (in print/issue): 01/05/2011

DOI:

10.4018/978-1-60960-569-8.ch013

\section{Document Version}

Publisher's PDF, also known as Version of record

\section{General rights}

Copyright for the publications made accessible via Ulster University's Research Portal is retained by the author(s) and / or other copyright owners and it is a condition of accessing these publications that users recognise and abide by the legal requirements associated with these rights.

\section{Take down policy}

The Research Portal is Ulster University's institutional repository that provides access to Ulster's research outputs. Every effort has been made to ensure that content in the Research Portal does not infringe any person's rights, or applicable UK laws. If you discover content in the Research Portal that you believe breaches copyright or violates any law, please contact pure-support@ulster.ac.uk. 


\section{Computer Games as Educational and Management Tools: Uses and Approaches}

Maria Manuela Cruz-Cunha

Polytechnic Institute of Cávado and Ave, Portugal

Vitor Hugo Costa Carvalho

Polytechnic Institute of Cávado and Ave, Portugal

Paula Cristina Almeida Tavares

Polytechnic Institute of Cávado and Ave, Portugal 
Senior Editorial Director:

Kristin Klinger

Director of Book Publications:

Julia Mosemann

Editorial Director:

Lindsay Johnston

Acquisitions Editor:

Erika Carter

Production Editor:

Sean Woznicki

Typesetters:

Print Coordinator:

Mike Brehm, Keith Glazewski, Natalie Pronio, Jennifer Romanchak, Milan Vracarich Jr.

Cover Design:

Jamie Snavely

Nick Newcomer

Published in the United States of America by

Information Science Reference (an imprint of IGI Global)

701 E. Chocolate Avenue

Hershey PA 17033

Tel: 717-533-8845

Fax: 717-533-8661

E-mail: cust@igi-global.com

Web site: http://www.igi-global.com/reference

Copyright (C) 2011 by IGI Global. All rights reserved. No part of this publication may be reproduced, stored or distributed in any form or by any means, electronic or mechanical, including photocopying, without written permission from the publisher. Product or company names used in this set are for identification purposes only. Inclusion of the names of the products or companies does not indicate a claim of ownership by IGI Global of the trademark or registered trademark.

\section{Library of Congress Cataloging-in-Publication Data}

Computer games as educational and management tools: uses and approaches /

Maria Manuela Cruz-Cunha, Vitor Hugo Carvalho, and Paula Tavares, editors.

p. cm.

Includes bibliographical references and index.

Summary: "This book considers the many uses of games and simulations, focusing specifically on their use in organizational and educational settings and providing perspectives on gaming for distance learning, gaming for rehabilitation, business simulators, and motivational games, this publication explores new and emerging trends in this ever-evolving area of research"-Provided by publisher.

ISBN 978-1-60960-569-8 (hardcover) -- ISBN 978-1-60960-570-4 (ebook) 1.

Management games. 2. Management--Simulation methods. 3. Organization--

Simulation methods. 4. Computer simulation. I. Cruz-Cunha, Maria Manuela, 1964- II. Carvalho, Vitor Hugo, 1979- III. Tavares, Paula, 1973-

HD30.26.C66 2011

658.3'124--dc22

2011012251

British Cataloguing in Publication Data

A Cataloguing in Publication record for this book is available from the British Library.

All work contributed to this book is new, previously-unpublished material. The views expressed in this book are those of the authors, but not necessarily of the publisher. 


\title{
Chapter 13 \\ Affective Educational Games and the Evolving Teaching Experience
}

\author{
Karla Muñoz \\ University of Ulster, UK \\ Paul Mc Kevitt \\ University of Ulster, UK \\ Tom Lunney \\ University of Ulster, $U K$ \\ Julieta Noguez \\ Tecnológico de Monterrey, Mexico \\ Luis Neri \\ Tecnológico de Monterrey, Mexico
}

\begin{abstract}
Teaching methods must adapt to learners'expectations. Computer game-based learning environments enable learning through experimentation and are inherently motivational. However, for identifying when learners achieve learning goals and providing suitable feedback, Intelligent Tutoring Systems must be used. Recognizing the learner's affective state enables educational games to improve the learner's experience or to distinguish relevant emotions. This chapter discusses the creation of an affective student model that infers the learner's emotions from cognitive and motivational variables through observable behavior. The control-value theory of 'achievement emotions' provides a basis for this work. A Probabilistic Relational Models (PRMs) approach for affective student modeling, which is based on Dynamic Bayesian Networks, is discussed. The approach is tested through a prototyping study based on Wizard-of-Oz experiments and preliminary results are presented. The affective student model will be incorporated into PlayPhysics, an emotional game-based learning environment for teaching Physics. PRMs facilitate the design of student models with Bayesian Networks. The effectiveness of PlayPhysics will be evaluated by comparing the students'learning gains and learning efficiencies.
\end{abstract}

DOI: $10.4018 / 978-1-60960-569-8 . \operatorname{ch} 013$

Copyright $($ 2011, IGI Global. Copying or distributing in print or electronic forms without written permission of IGI Global is prohibited. 


\section{INTRODUCTION}

Space and flight simulators signaled the beginning of a new revolution for training, teaching and learning (Bergeron, 2006). Technology has made remarkable progress in computing and electronics, which have converged in the game development area. Students have grown up playing video games, exposed to a large quantity of visual and acoustic stimulus and inhabit a world strongly influenced by Information Technology (IT). As a result, achieving knowledge, understanding and motivation during the teaching-learning experience has become more challenging (Oblinger, 2004). The ultimate goal has been to create enhanced learning environments that will be able to deal successfully with the learners' expectations. Intelligent gamebased learning environments, e.g. educational games, facilitate teaching through experience by offering immediate feedback and engaging the learner's attention (Squire, 2003). As a result, an emotional link is established between the learner and the game. This feature results in these game environments becoming straightforward motivational tools.

Game-based learning environments must follow design approaches and principles that make them capable of offering effective learning (Schaller, 2005). Learning goals must lead and encourage the learner's exploration. An assessment criterion must be incorporated to evaluate the learner's skills and performance, and to distinguish the knowledge topics that are understood and mastered by the student from those which are lacking. It is important to note that learning to play a game effectively does not ensure mastering the domain knowledge, since games are composed of a set of rules, which define the gameplay, that are not necessarily related to the learning content. Suitable feedback must be provided when a learning need is identified. Therefore, Intelligent Tutoring Systems (ITSs) are incorporated into the architecture of intelligent game learning environments (Conati \& Maclaren, 2009), since
ITSs encourage independent learning and provide adaptable responses according to each student's pace, form of learning and history of interaction.

On the other hand, emotion has been shown to influence learning and performance. Emotion, cognition and motivation are deeply interrelated (Pekrun, Frenzel, Goetz, \& Perry, 2007). Hence, research is focused on enhancing the learner's understanding and engagement by intelligently and effectively managing the affective aspects of educational games. The aim is to communicate effectively an emotional state, which will change the learner's disposition and emotional states to those that facilitate learning and understanding (Conati \& Maclaren, 2009). However, to know if the desired effects will be achieved, it is necessary to enable these systems to identify the learner's affective or motivational states. Finding a solution to this challenge has been the focus of several research areas, e.g. Affective Computing, ITSs and Game-based Learning Environments. Affective Computing focuses on enabling computers to express and recognize emotion (Picard et al., 2004). ITSs are currently being enhanced to incorporate the emotional dimension into their framework. This chapter focuses on the specific challenges of how to design effective game-based learning environments, how to identify the learner's emotional state and how to adapt and respond to the learner's actions and disposition. To attain this objective the state of the art of Intelligent Game Learning Environments, ITSs and Multimodal Output Adaptation related to Affective Computing is first discussed. An affective student model, which infers the learner's emotional states from cognitive and motivational variables, is proposed. To infer emotion an approach focusing on analyzing the learner's observable behavior, qualitatively and quantitatively, is applied. A methodology of designing an affective student model using Probabilistic Relational Models (PRMs), e.g. Bayesian Networks(BNs), is described. The affective student model is based on the Control-Value theory of 'achievement emotions'. PlayPhysics, 
an emotional intelligent game-based learning environment for teaching Physics at undergraduate level, is introduced.

To evaluate the affective student model and test the approach, a prototyping study based on Wizard-of-Oz experiments was carried out. Once the accuracy of the model has been verified, the model will be incorporated into the Olympia architecture. The Olympia architecture is described. PlayPhysics'teaching effectiveness will be evaluated through the comparison of students' learning gains and learning efficiencies. Finally, this chapter concludes by highlighting the advantages of using a PRMs approach for student modeling, applying game-based learning environments for teaching and learning and incorporating affective ITSs. A preliminary prototyping exercise was conducted with the affective student model to determine if the identified variables are sufficient to infer accurately the learner's emotional state. When a reliable model of the learner's emotional state has been developed, the research will focus on enabling PlayPhysics to provide a response that accomplishes the maximum learning gain or that alters the learner's emotional states to optimize learning and understanding. Dynamic Decision Networks (DDNs) will be applied to tutor modeling. The effectiveness of PlayPhysics for teaching linear momentum, vectors, circular movement and movement of rigid bodies at undergraduate level will be evaluated.

\section{BACKGROUND}

Computer games are used as educational resources, since one approach to learning is through experience. Therefore, actively involving the student in the learning process has achieved enhanced learning gains and improved understanding more effectively than a passive approach, where the student simply listens (Sykes, 2006).

\section{Computer Games as Ideal Learning Tools}

Computer games reward the mastering of a skill or ability in diverse ways such as incrementing the score and advancing the narrative. In addition, games easily attain the learner's attention, offer immediate feedback and encourage independent learning. Squire (2003) discusses that educational games enhance the teaching-learning experience through eliciting intense emotional responses. Research has also been focused on the use of games for assisting in the analysis of the learner's patterns of interaction to create more effective game designs, enhancing the understanding of the impact of technology on individuals.

Sounds and visual media have proven effective at influencing a game's playability, since audio and visuals can communicate to, or create in, the learner a positive mood or emotion (Malone, 1981). Malone (1981) also signaled that the sense of fantasy created by the game narrative also influences the learner's emotional state and personal disposition to play, since it enables emotional mastery over a specific event. The problem is creating a game that suits the personal demands of a spectrum of users. The semantics of colors can be used by video games to communicate feelings, e.g. cold colors can cause the user to feel detached from the environment, manage the user's attention, e.g. bright colors easily attract the user's attention, provide physical and psychological features to game characters, show an object's function and indicate a change in game progression (Zammitto, 2005). However, other in-game factors have been shown to affect the user's willingness to play, e.g. complexity, variability, novelty of the stimuli, the level of experience, personality, gender and the reinforcement of positive or negative behavior (Chumbley \& Griffiths, 2006).

To be effective, an educational game has to incorporate specific characteristics into its design. Challenge, curiosity, fantasy and control are features signaled by Malone and Lepper (1987). 
Challenge is achieved through specific learning goals, different levels of difficulty and unpredictability. A sense of control is created through enabling the learner to make choices, the effects of which can be perceived and experienced. Cognitive and sensory curiosity has to be encouraged during the learning experience and usually audio and visual media are used for this purpose. The learner's emotional and thinking processes are highly correlated with the game fantasy. Therefore, the narrative should target the learner's emotional and cognitive expectations, e.g. metaphors and analogies, and should accurately incorporate domain knowledge. The provision of feedback plays a central role in the teaching-learning experience and has to be unambiguous, effective and recurrent. Building an effective educational game involves defining effectively gameplay and user interaction, integrating domain-specific and game development techniques, integrating software and hardware interfaces, implementing the students' preferred learning styles, creating standards for implementing content and code and implementing an assessment criterion (Bergeron, 2006).

The achievement of learning goals and the mismatch between game content and curriculum content are factors that contribute to lecturers' skepticism on using educational games as a tool to enhance the teaching-learning experience. Therefore, lecturers, who are accustomed to employing conventional means, resources and tools for teaching, perceive the acquisition of learning games as a non-secure investment (Carpenter \& Windsor, 2006). Accordingly, educational games also have the challenge of targeting the lecturers' requirements for specific domain knowledge. Although some lecturers are familiar with the use of conventional tools for teaching, it is a fact that the form of education delivery has to evolve to suit the students' expectations. Students are living in a world highly influenced by IT, e.g. communicating, searching and socializing through the Internet are perceived as common, familiar and comfortable tasks. These students are known as
'Millennials' or 'Net Generation'(Oblinger, 2004) and are highly attracted by environments that are able to provide an enhanced sensorial experience through the incorporation of diverse media, e.g. sounds and visuals.

\section{Intelligent Game-Based Learning Environments}

The applications and target populations of gamebased learning environments have been diverse. As an example, educational games have been used for teaching children and adolescents strategies for dealing with depression (Brezinka \& Hovestadt, 2007), for teaching children Mathematics (Conati \& Maclaren, 2009) and for teaching adolescents Electrostatic principles (Barnett, Squire, Grant, \& Higginbotham, 2004). It is evident that to attain acceptance as effective learning tools, gamebased learning environments have to incorporate an intelligent assessment criterion that identifies when the student has achieved the learning goals. Accordingly, to support independent learning, suitable and adaptable feedback according to the detected learner's needs must be provided. Intelligent Tutoring Systems (ITSs) are a computer tutoring approach that applies Artificial Intelligence (AI) principles to disconnect the logic of interaction from the domain knowledge (Clancey \& Buchanan, 1982). ITSs follow student performance over time, to implement diverse pedagogical methods and techniques and to adapt intelligently to each student over time. Therefore, ITSs are incorporated into the architectures of game-based learning environments. ITSs comprise a domain model, student model, teaching model, communication module and a Graphical User interface (GUI). Research in the area of ITSs has focused on each one of these components. However, the main challenges have been selecting and communicating suitable pedagogical responses and accurately representing the student and the domain (Du Boulay \& Luckin, 2001). 
The student model enables the ITS to understand the information and requirements of each student (Sucar \& Noguez, 2008). In addition to allowing knowledge of the cognitive state of the learner, the student model can also identify the learner's emotional (Conati \& Maclaren, 2009) or motivational (Rebolledo-Mendez, Du Boulay, \& Luckin, 2006) states. Emotion influences learning and performance and is deeply intertwined with cognitive and motivational constructs (Pekrun et al., 2007). Affective gaming arises from the union of the Affective Computing field (Picard et al., 2004) with the Digital Games field and focuses on influencing and identifying the player's emotional state (Sykes, 2006). Emotions can be used by computers for evaluating the user's experience, understanding when the emotion is relevant to the learning experience and when it can be safely ignored, predicting the learner's behavior and controlling the game. Making machines capable of recognizing and expressing emotion promises to enhance the user's experience, e.g. improved learning, engagement, motivation and training.

\section{Identifying the Learner's Emotional and Motivational States}

The approaches applied by ITSs to infer or recognize the learner's emotional state are:

1. Recognizing the physical effects of emotion

2. Predicting emotions from their origin

3. A hybrid approach using the previous two approaches

4. Reasoning about the learner's observable behavior

For recognizing the physical effects of emotion, cameras, microphones and sensors are employed to collect information from gestures, prosodic features and body positions and signals respectively (D’Mello, Craig, Witherspoon, McDaniel, $\&$ Graesser, 2008). This information is mapped to emotional states. The challenge of this approach is to acquire large quantities of data that will be classified through AI mechanisms, e.g. Artificial Neural Networks (ANNs). In addition, the effects are modeled through the observations of peers, i.e. lecturers and students, and trained judges. Hardware may be perceived as intrusive and may be prone to failure. Also this approach is not suitable for online learning, since students usually have to travel to special laboratories for interacting with these systems (Burlenson \& Picard, 2007). Ekman and Friesen (1978) signaled that there is universality in facial expressions to convey an emotional message, and as a result, research has been undertaken that maps facial expressions to an affective state.

The Ortony, Clore and Collins (OCC) model is a cognitive theory of emotion that has often been applied to inferring emotion from its origin (Chalfoun, Chaffar, \& Frasson, 2006). This theory explains how emotion arises according to the interplay of a user's goals with events and a user's standards and attitudes (Ortony, Clore, \& Collins, 1990). Therefore, this approach reasons about the potential cognitive antecedents of emotions and infers their existence over time. The challenges of this approach are, being aware of the learners' standards and attitudes and assessing the learner's goals. A hybrid approach predicts whether the emotion will happen according to the antecedents' existence. To know if the emotion actually happened, the effects have to be identified and compared with the prediction. This hybrid approach inherits the challenges of both approaches (Conati \& Maclaren, 2009). Jaques \& Vicari (2007) attempted to infer emotion from its origin using the learner's observable behavior. One challenge of applying the OCC model to inferring the learner's emotional state is to adapt the theory to the learning context. Jaques \& Vicari (2007) built two student models describing two kinds of students: one seeking to master the topics and another focused purely on performance. Effort was measured qualitatively and quantitatively during the learner's interaction. The work of Del 
Soldato \& Du Boulay (1995) formed a basis for representing the learner's effort. Jaques \& Vicari (2007) do not present any results on the accuracy of their approach. To date, no system is able to identify the relevant learner's emotions.

Del Soldato \& Du Boulay (1995) applied a qualitative and quantitative approach to infer the learner's motivational state from observable behavior. This approach was based on Keller's Motivational Design Model (Keller, 2006). The approach focuses on analyzing the learner's actions and decisions and mapping them qualitatively and quantitatively to effort, independence and confidence. This approach was employed by MEcolab, which is an educational game for teaching ecology and it proved to be effective (RebolledoMendez et al., 2006). Self-efficacy was signaled as an important measure of the student's disposition to learn (Del Soldato \& Du Boulay, 1995). Self-efficacy involves the learner's beliefs about being able to perform a specific learning task, achieving a specific level of performance and the perceived control over the task, e.g. skills and knowledge. Therefore, McQuiggan, Mott, and Lester (2008) built a learner's self-efficacy model. The model infers the learner's self-efficacy from observable behavior and physiological data. Using only observable variables, the model achieved $70 \%$ accuracy and the accuracy of the model increased by $10 \%$ on incorporating physiological data. Models that infer the learner's emotions from observable behavior are not effective, but inferring the learner's motivational state and self-efficacy level using observable behavior has been more successful. Furthermore, to date, there is no student model that can completely integrate motivational and emotional aspects. Hence, this research is mainly focused on building a student model that can use motivational and cognitive variables to infer the student's emotional state for intelligent gaming. In the section, 'An Affective Student Model for Intelligent Gaming', the series of steps performed for building the affective student model will be discussed in detail. In addition, the motivational and cognitive theory employed to infer emotion from cognitive and motivational variables is described.

\section{Multimodal Output Communication and Adaptation}

Providing feedback is a key factor in the teachinglearning process. The pedagogical strategies that can be selected may be focused on enhancing understanding or motivation. Research has shown that it is important to classify pedagogical actions in order to be able to identify when motivational and cognitive strategies are in contraposition, complement each other or are independent (Lepper, Woolverton, \& Mumme, 1993). The aim is to select the action that will maximize understanding or motivation. To enhance the communication of pedagogical responses, research has been focused on the creation of Embodied Pedagogical Agents (EPAs) (D'Mello et al., 2008; Conati \& Maclaren, 2009) and Synthetic Characters (Dias et al., 2006). The ultimate challenge is to attain believability (Johnson, Rickel, \& Lester, 2000), which has encouraged research in the state of the art of animation, emotional intelligence, common sense, sociology, distributed architectures, multimodal output adaptation and cinematography. EPAs that comprise the communication module of ITSs (D'Mello et al., 2008; Conati \& Maclaren, 2009) convey a feedback response, which includes data derived from the student model.

The synchronization of the behaviors of Herman, the EPA of the learning-environment Design a Plant, is done through establishing hierarchical dependencies between behaviors and classifying audio and visual media through setting diverse types of indexes (Stone \& Lester, 1996). The EPAs' animation space, which comprises their behavior, can be defined by full-body and compositional animations, such as Cosmo's animation space (Lester, Voerman, Towns, \& Callaway, 1999). Visual languages are derived to achieve synchronization (Cassell, Högni Vilhjálmsson, \& 
Bickmore, 2001; Bates, Loyall, \& Reilly, 1992). EPAs can be implemented as self-determined entities, which react according to the changes in their virtual environment or can be controlled by a central entity, such as computer-controlled characters in video games (Mateas, 1997). To attain a reactive behavior, some EPAs are implemented using a cognitive theory of emotion as a basis (Bates et al., 1992), such as the OCC model, or a personality theory (Conati \& Maclaren, 2009), such as Big Five. Computer and educational games are comprised of audio and visual media that serve diverse communication functions, such as creating a sense of immersion, setting a mood and decreasing the player's learning curve (Collins, 2008; Malone, 1981). In addition, colors can convey different emotional states and moods (Kaya, Epps, \& Hall, 2004). Research has intelligently employed color to report the learner's emotional state in virtual learning environments (Razek, Chaffar, Frasson, \& Ochs, 2006) and classrooms (Alsmeyer, Luckin, \& Good, 2008). Colors have also been used to express and emphasize emotion (Nijdam, 2005). Our research will focus on selecting the most suitable feedback responses to maximize learning or understanding. Therefore, we choose to modulate game-elements, such as visuals, audio and colors, to influence the learner's emotional state and convey cognitive, motivational and emotional responses. The implementation of these features is described in the, 'PlayPhysics design', section.

\section{METHODOLOGY}

This section describes the research methodology applied to create and evaluate an affective student model, which infers emotion from motivational and cognitive variables using observable behavior. In addition, the design of PlayPhysics is discussed and described signaling how game-features will be modulated to deliver pedagogical responses.

\section{An Affective Student Model for Intelligent Gaming}

The theory of emotion, acting as a basis for building the affective student model, is described in this section. This model infers the learner's emotions from cognitive and motivational variables through observable behavior. The learner's attitudes, beliefs and social standards are determined through answers to questions posed as part of a game dialogue. In addition, the advantages of applying Probabilistic Relational Models (PRMs) to student modeling are outlined.

\section{The Control-Value Theory of Achievement Emotions}

The control-value theory of 'achievement emotions' is a cognitive and motivational theory of emotion (Pekrun, 2006; Pekrun et al., 2007). It comprises motivational, cognitive, affective, expressive and physiological aspects. 'Achievement emotions' are emotions that arise when performing academic or achievement activities in which the attainment of a desired outcome is expected. The theory signals that control and value appraisals are the most relevant to determining an emotion. Control, e.g. self-efficacy, is defined as the perceived control over the activity and the outcome. Value is related to the perceived importance of the outcome and the desirability and relevance of the activity. Appraisals of control that are relevant to determine 'achievement emotions' are situationoutcome, activity-control and action-outcome expectancies. Situation-outcome expectancies relate to evaluation as to whether an action is or is not required to attain the desired outcome in the specific situation. Activity-control expectancies are related to confidence beliefs when starting and performing a specific action. Action-outcome expectancies are related to beliefs that specific actions can facilitate or can prevent the attainment of specific outcomes. These outcomes can be positive or negative. The causal attributions of outcomes 
are perceived as situation-outcome expectancies when the outcome is attributed to external causes and are perceived as action-control and action-outcome expectancies when the outcome is attributed to internal causes. Internal causes are defined as the learner's actions, circumstances, skills and abilities. External causes are related to another's actions, circumstances, skills and abilities. Intrinsic-values and extrinsic-values are relevant when determining the subjective value of actions and outcomes. These values are related to evaluating the activity and the outcome per se, i.e. intrinsic, or evaluating them for other goals, i.e. extrinsic.

Control-value theory is an integrative framework of assumptions corresponding to other emotional theories, such as expectancy-value theories of emotion, theories of perceived control and attributional theories of achievement emotions. Therefore, this theory, rather than challenging the OCC model (Ortony et al., 1990), incorporates some of its assumptions. The theory classifies 'achievement emotions' into three types according to their focus and time frame: prospective outcome, retrospective outcome and activity emotions. The basic assumptions of the control and value appraisals are summarized in Table 1. The prospective outcome emotions arise from the expectations of succeeding or failing. The retrospective outcome emotions focus on the attribution of success and failure and the activity emotions are determined by the activity demands and the person's disposition to participate, which are mapped to perceived control over the activity and its value. It is important to signal that 'achievement emotions' are the result of the product of appraisals of control and value and that if one of these is lacking no-emotion is induced. In addition, achievement emotions are domain dependent, e.g. the emotions arising in a History domain will be different from the ones arising in a Physics domain. The Control-value theory has proven effective at recognizing the learners' emotions in the English, German, Math and Physics domains (Goetz, Frenzel, Pekrun,
Hall, \& Lüdtke, 2007). The method used by Goetz et al. (2007) is the self-report of emotions using the Achievement Emotions Questionnaire (AEQ), which was designed and validated through Structural Equation Modeling (SEM) (Pekrun, Goetz, \& Perry, 2005).

\section{Student Modeling and Probabilistic Relational Models (PRMs)}

Modeling the user's behavior and related data is a task that involves uncertainty (Sucar \& Noguez, 2008). In the learning context, there are still questions about how the learner achieves knowledge and understanding. In addition, the personal differences between learners, e.g. diversity between attitudes, standards, beliefs and goals, make it more difficult to ensure that the learner is experiencing a determined emotion in a specific situation or domain. Also, deciding which information has to be taken into account to update the student model represents a challenge. Therefore, as a solution to this problem, Bayesian Networks (BNs) have been applied to modeling. BNs are AI tools applied to domains with inherent uncertainty. BNs are graphs that represent causal relations between random variables or events (Jensen \& Nielsen, 2007) and have been applied to building cognitive (Noguez \& Sucar, 2006, Muñoz, Noguez, Mc Kevitt, Neri, Robledo-Rella, \& Lunney, 2009) and affective student models (Conati \& Maclaren, 2009). The main effort in designing BNs lies in the time that must be invested in selecting meaningful information from the knowledge domain and the resultant complexity of the Bayesian Network (BN), i.e. the number of random variables is large and each node has more than three parents with several states. To facilitate the design of student models with BNs, probabilistic relational models (PRMs) are used (Sucar \& Noguez, 2008). PRMs are an object-oriented representation of the knowledge domain that can be easily transformed into a BN or several BNs. Their representation facilitates applying the model to several domains and the 
Table 1. The Control-value theory of achievement emotions (Pekrun et al., 2007, p. 20)

\begin{tabular}{|c|c|c|c|}
\hline Object focus & $\begin{array}{l}\text { Appraisals } \\
\text { Value }\end{array}$ & Control & Emotion \\
\hline \multirow[t]{2}{*}{ Outcome/ Prospective } & Positive (Success) & $\begin{array}{l}\text { High } \\
\text { Medium } \\
\text { Low }\end{array}$ & $\begin{array}{l}\text { Anticipatory Joy } \\
\text { Hope } \\
\text { Hopelessness }\end{array}$ \\
\hline & Negative (Failure) & $\begin{array}{l}\text { High } \\
\text { Medium } \\
\text { Low }\end{array}$ & $\begin{array}{l}\text { Anticipatory Relief } \\
\text { Anxiety } \\
\text { Hopelessness }\end{array}$ \\
\hline $\begin{array}{l}\text { Outcome/ Retrospective } \\
\text { Activity }\end{array}$ & $\begin{array}{l}\text { Positive (Success) } \\
\text { Negative (Failure) } \\
\text { Positive } \\
\text { Negative } \\
\text { Positive/Negative } \\
\text { None }\end{array}$ & $\begin{array}{l}\text { Irrelevant } \\
\text { Self } \\
\text { Other } \\
\text { Irrelevant } \\
\text { Self } \\
\text { Other } \\
\text { High } \\
\text { High } \\
\text { Low } \\
\text { High/Low }\end{array}$ & $\begin{array}{l}\text { Joy } \\
\text { Pride } \\
\text { Gratitude } \\
\text { Sadness } \\
\text { Shame } \\
\text { Anger } \\
\text { Enjoyment } \\
\text { Anger } \\
\text { Frustration } \\
\text { Boredom }\end{array}$ \\
\hline
\end{tabular}

inference complexity is reduced, since parts of the model can be used with instances of a larger model. The domain is divided into classes, $\mathrm{X}_{1}, \mathrm{X}_{2}$, $\ldots, X_{n}$, with each class comprised of attributes $A_{i j}$ $\epsilon \mathrm{A}\left(\mathrm{X}_{\mathrm{i}}\right)$ and each attribute corresponds to one or more values $\mathrm{V}\left(\mathrm{A}_{\mathrm{ij}}\right)$ of a specific domain (Sucar $\&$ Noguez, 2008). The dependencies are defined at class level using a relational structure, where attributes of a class can depend on attributes of other classes. The conditional probabilities of PRMs are defined in the same way as the conditional probabilities of BNs, i.e. defining the Markov Blanket for each attribute, e.g. parents and children.

\section{Building the Affective Student Model}

The PRM structure corresponding to the learner's emotions is shown in Figure 1. This model was based on the control-value theory of 'achievement emotions'. The dashed lines describe relations between classes and the arrows represent conditional probabilistic dependencies. Three Dynamic Bayesian Networks (DBNs) were derived from this PRM. Each DBN corresponds to one of the emotion types defined by Pekrun et al. (2007), i.e. prospective outcome, activity and retrospective outcome emotions. The DBNs were built using observable variables that are related to the learner's interaction behavior. Control and value appraisals are inferred from the state of these random variables, which were identified from the work by Del Soldato \& Du Boulay (1995), McQuiggan et al. (2008) and Pekrun et al. (2005). Initially this work focuses only on motivational and cognitive variables, since from the work of McQuiggan et al. (2008), it was noted that physiological variables may result in improved model accuracy. In addition, the existence of an emotion cannot be ensured by using as direct evidence physiological patterns (Pekrun, 2005).

The DBN corresponding to outcome-prospective emotions, hope, anticipatory joy, anticipatory relief, anxiety and hopelessness, is shown in Figure 2. Control and value appraisals are inferred from variables related to the learner's motivation, e.g. confidence and effort, and from variables related to the learner's cognition, e.g. the latest level of performance and level of difficulty. Control $_{t-1}$ and Value $_{t-1}$ represent the probabilities that are transferred over time from the DBN corresponding to outcome-retrospective emotions, 
Figure 1. PRM structure for the learner's emotions based on the control-value theory

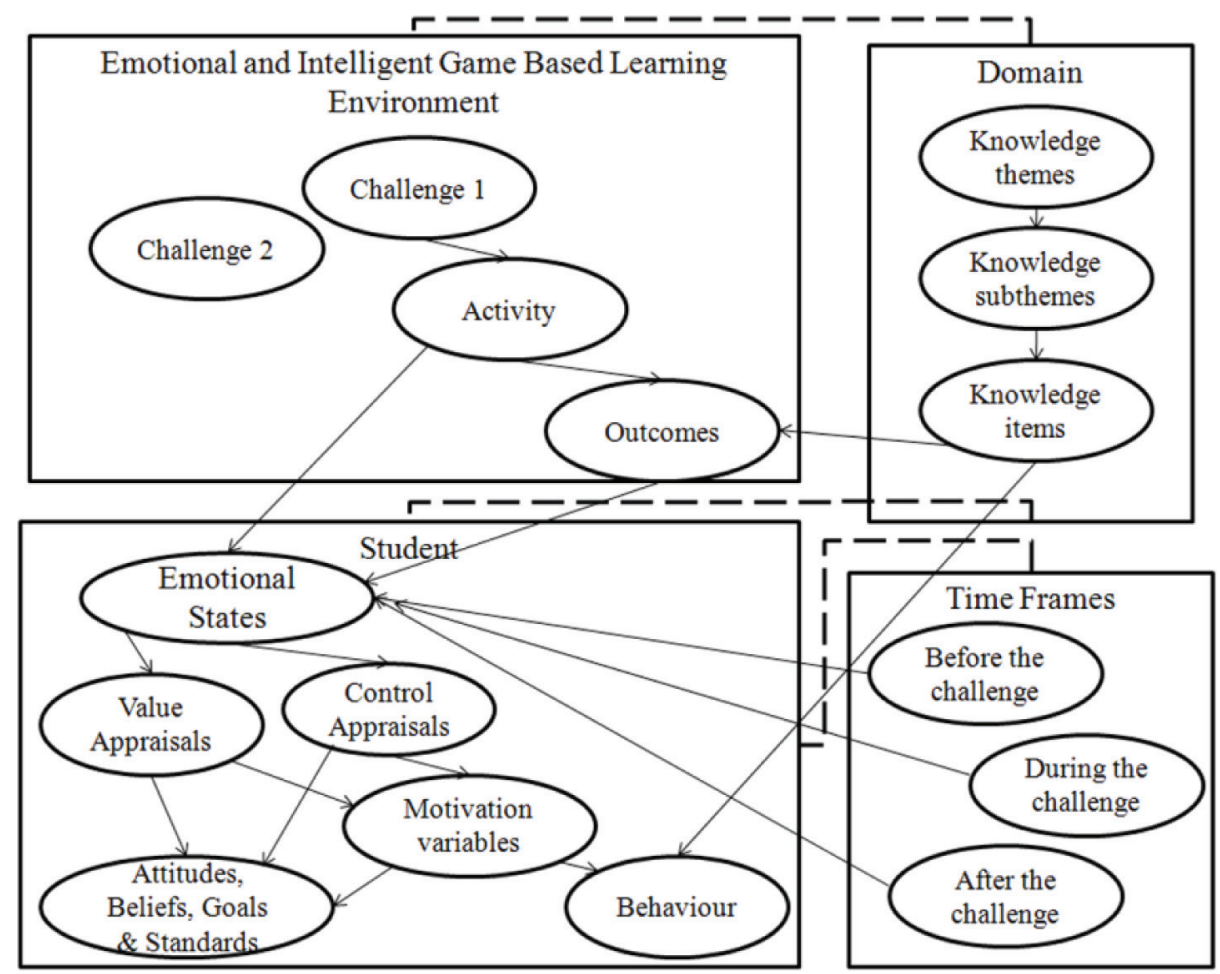

which are related to the learner's attributions of previous failure or success. Control ${ }_{t+1}$ and Value ${ }_{t+1}$ represent the probabilities that are transferred from the outcome-prospective emotions DBN to the activity emotions DBN, i.e. the influence that the student's expectations have on the emotion experienced while performing the specific learning activity.

As stated previously, inferring emotion from its origin must address assessing the learner's attitudes, goals, standards and beliefs. The theory of Planned Behavior (Ajzen, 2005) uses a qualitative and quantitative approach to assess a person's behavioral intention, i.e. to know if the goal exists. The approach involves designing and building a questionnaire, which addresses the qualitative and quantitative assessment of a person's attitudes, standards and control beliefs (Francis et al., 2004). Using Ajzen's approach as a basis, we employ 'answers to posed questions'. For the purposes of our research, these questions were defined as part of the game narrative, which occur in cut-scenes during game dialogues.

To evaluate the affective student model a prototyping study based on Wizard-of-Oz experiments (Höök, 2005) will be carried out with students of Physics at undergraduate level. The students are asked to:

1. Take a pre-test (the score is noted as soon as the students finish the test).

2. Answer the questions posed in the game dialogue.

3. Solve a Physics problem, which will be implemented as a game challenge of PlayPhysics.

4. Get permission from the student to publish the problem-solving results.

Steps 1-2 (above) assist with evaluating the accuracy of the questions and the answers created to acquire the evidence corresponding to 
Figure 2. Outcome-prospective Emotions DBN

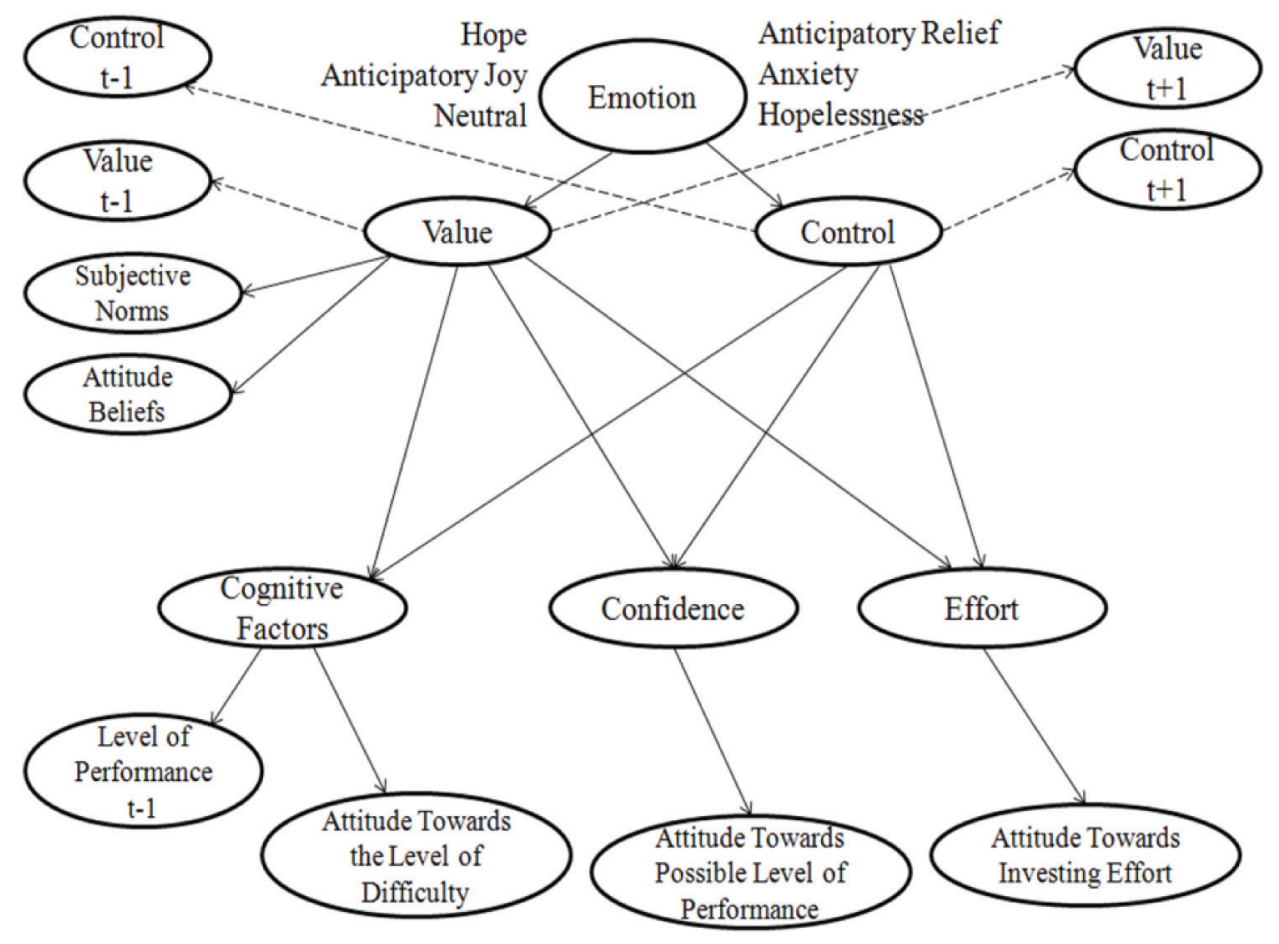

the random variable of the outcome-prospective emotions DBN. The pre-test also allows us to determine the learner's previous knowledge and experience at solving-problems regarding the related Physics topics. A preliminary evaluation of these two points was carried out with seven students at postgraduate level at the University of Ulster. Results are shown and analysed in the section, 'Results and Discussion'. The emotions reported by the participants were compared with the emotions inferred by the outcome-prospective emotions DBN. The objective of this phase is to achieve a preliminary evaluation of the DBN and to identify possible problems in the prototyping material that will be used to test the affective student model with students.

Step 3 in the process has the objective of identifying activity emotions and outcome-retrospective emotions. To achieve an accurate evaluation, we will locate each student with a lecturer in a Gesell dome, see Figure 3, where two lecturers can observe their interaction behind the mirror and make the corresponding annotations for the observed random variables. These observations will be introduced in the corresponding DBNs and the DBNs' prediction will be compared with the emotion reported by the students. Step 4 in the process will be employed to find out how relevant the students feel that the outcome is, and to determine how important it is for the students to compare their performance with the outcome obtained by other students on the same Physics course.

\section{PlayPhysics Design}

Once the proposed affective student model has been formalized, it will be incorporated into the Olympia architecture. PlayPhysics is an emotional games learning environment for teaching Physics at undergraduate level. This section describes the features of the generic and affective architecture, 
Figure 3. Setting for the Prototyping Study of the Affective Student Model

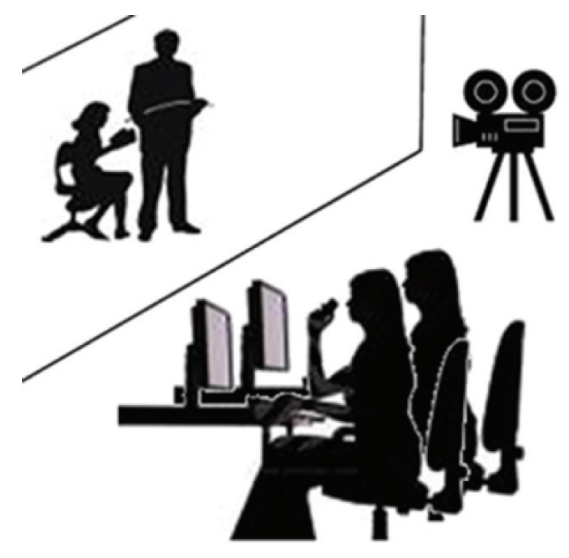

Olympia. In addition, the game-design, the cognitive student model and the selection and implementation of pedagogical responses are discussed.

\section{Affective Olympia Architecture}

PlayPhysics is an application of the Affective Olympia architecture shown in Figure 4. Olympia is an enhanced version of the generic architecture introduced by Noguez \& Sucar (2005) and refined in Sucar \& Noguez (2008). Olympia has proven effective for building game-based virtual learning environments and teaching Physics at undergraduate level (Muñoz et al., 2009). Here, Olympia is enhanced to enable it to infer the learner's emotional state and implement cognitive, motivational and affective actions, which will improve the learner's level of engagement, learning and understanding. The motivational and affective actions will be delivered using game elements such as visuals, sounds and colors.

Olympia is comprised of static and dynamic interactive modules. These modules are incorporated to enable a virtual learning environment to depict the interaction level of an educational game. The difference between a static and a dynamic module is in its adaptability. A static module changes in real-time according to the pedagogical, motivational and affective actions, whilst a dynamic module changes according to the decisions taken by the presentation content manager module. According to this classification, the function of each module is described below.

Static interaction modules:

1. Physics and collisions module contain all the physics-and-math driven objects increasing the level of realism during simulation.

2. Input detection module senses and handles the user's input.

3. Networking module transmits data across the network.

4. Utilities module contains other tools such as timers and resource managers.

5. Scripting module enables external control of the application.

Dynamic interaction modules:

1. Emotional feedback module uses sound and color tailored to the student's mood.

2. Interactive AI module determines the behavior of non-player characters in the scene, enhancing believability.

3. Graphics Look \& Feel rendering module contains the real-time visual resource management.

Olympia represents a semi-open learning environment (Bunt \& Conati, 2003) where specific learning goals direct the learner's interaction with the virtual world and the simulator. Olympia combines a game-based learning environment with an ITS. The action-challenge relation is handled by the Game mechanics module through the game rules. The Teaching \& Learning AI module comprises an ITS. The interface analysis module decides which events are relevant to be analyzed by the behavior analysis module. Once evaluation of the events has been completed, the evidence provided is propagated to the student model. The 
Figure 4. Affective Olympia architecture

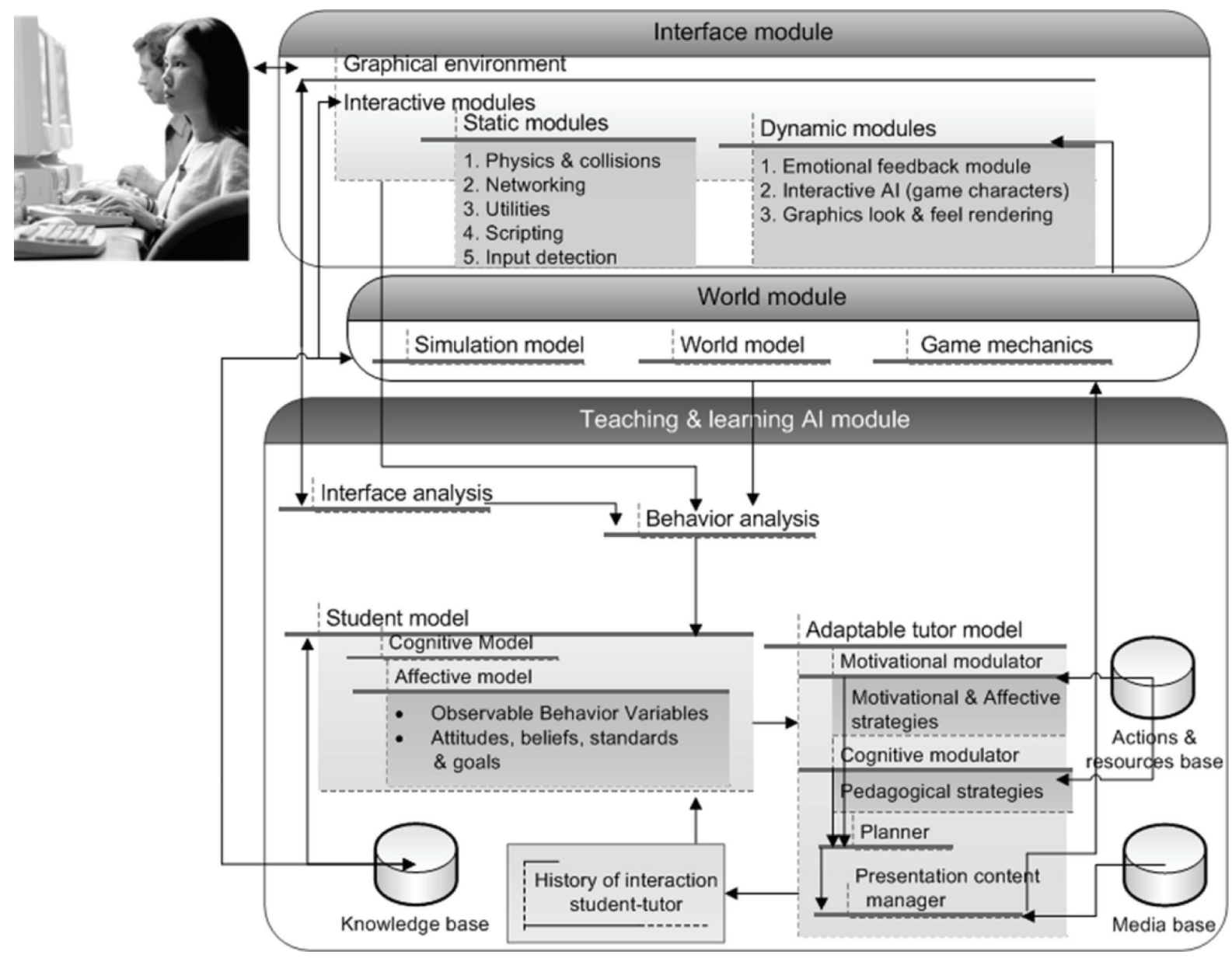

student model comprises cognitive and affective models, which are employed to infer the learner's cognitive and emotional states. These models were implemented using a PRMs approach and DBNs as AI tools. Once the student model executes the inference mechanisms, the results are forwarded to the adaptable tutor model. The tutor model selects the pedagogical, motivational or affective action or actions that maximize the student's learning, understanding or level of engagement. These actions are handled by the cognitive and motivational modulators. According to the strategies selected by the planner, the presentation content manager module makes the necessary changes in the game mechanics and the world model. The changes made to the world model and the game mechanics influence the behavior of the dynamic interactive modules. The tutor model will be implemented using Dynamic Decision Networks (DDNs), e.g. Influence Diagrams, which enhance the potential of DBNs through the incorporation of utility and decision nodes (Jensen \& Nielsen, 2007).

Olympia architecture is perceptual, intelligent, adaptable and multimodal. Its perceptual feature relates to the ability to infer the learner's cognitive and emotional states during the learner's interaction. It is intelligent, since it uses AI tools to handle uncertainty involved in the teaching learning experience, e.g. DBNs and DDNs. Its adaptable feature is capable of adjusting pedagogical, 
Figure 5. The most difficult topics of an introductory Physics course

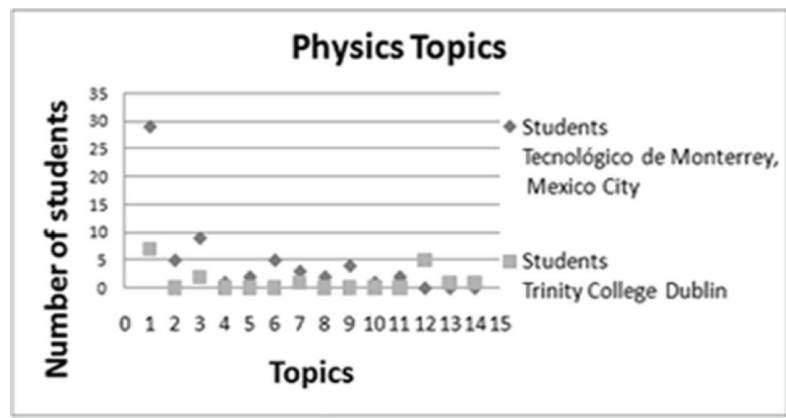

1.Mechanics (Cinematic \& Dynamic - circular), 2. Parabolic movement, 3. Vectors 3D, 4. Free fall, 5 .Work, 6 . Friction - circular, 7. Free body diagrams, 8 . Mass centre, 9. Collisions \& momentum, 10. Relative velocity. 11. Energy, 12. Wave motion, 13. Light, 14. Modern Physics

motivational and affective actions to the learner's needs. It is multimodal, since to communicate the chosen actions, it modulates, integrates and synchronizes game elements and features.

\section{Game Design}

PlayPhysics is an emotional game-based learning environment and an application of the Olympia architecture. It is being developed for teaching Physics at undergraduate level. An online requirements analysis survey was conducted with lecturers and students of Physics at Tecnológico de Monterrey, Mexico City campus (3 lecturers and 35 students) and Trinity College Dublin (1 lecturer and 18 students). The students were enrolled on an introductory Physics course at undergraduate level and their age is about 17 and 23. The objective was to indentify the most challenging and meaningful topics in an introductory Physics course in order to create the game challenges. In addition, the learners' preferred methods for providing feedback and engagement were analyzed. Therefore, PlayPhysics focuses on covering Mechanics (specifically Newton's laws, circular movement and movement of rigid bodies), Vectors, Linear Momentum and Collisions, as shown in Figure 5.
PlayPhysics' game story is a space adventure, where the learner is an astronaut, a lieutenant, whose spaceship will navigate towards the space station Athena. Athena is controlled by the supercomputer, VNUS-27-81. VNUS was infected with a harmful virus and as a result it attacked Athena's crew. The captain, Richard Foster, could not escape from the space station Athena with all the crew. Foster, as part of the story, is the learner's mentor. NASA realizes that the lieutenant's spaceship is at the point of being launched and proceeds to contact him or her. NASA explains the situation and asks for the lieutenant's help to rescue Foster and recover control of Athena. To attain these goals the learner has to apply his or her knowledge of introductory Physics. An example of a game dialogue in a cut-scene is shown in Figure 6. This game dialogue takes place before the learner starts to interact with the first challenge. This question is related to the learner's confidence beliefs. A positive, neutral or negative belief is inferred in the form of a probability distribution.

\section{Case Study}

The first challenge of PlayPhysics is to safely dock the spaceship, Alpha Centauri, on the Athena space station, which orbits around the sun between the 
Figure 6. Fragment of a PlayPhysics game dialogue

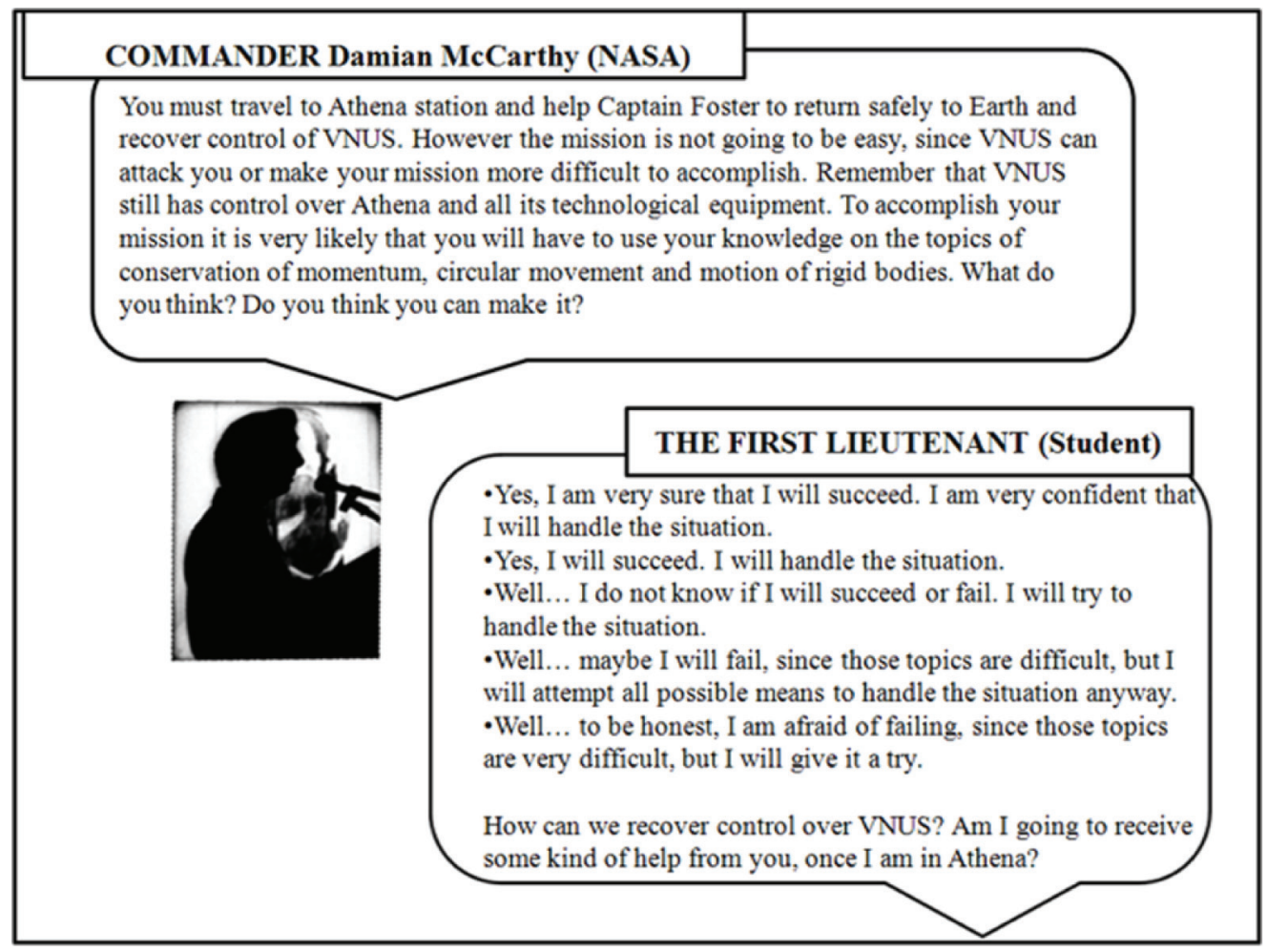

orbits of Mars and Jupiter. The station is shaped like a donut as shown in Figure 8. Athena is rotating with a constant angular velocity to create an artificial gravity $\left(\mathrm{g}=9.8 \mathrm{~m} / \mathrm{s}^{2}\right)$. The lieutenant, the student has to navigate Alpha Centauri by applying Newton's laws of motion for particles and rigid bodies. In addition, the student has to know the topics of vectors and linear and circular kinematics. To make the problem non-trivial, the values corresponding to Alpha Centauri's initial location and velocity with respect to Athena are initialized randomly. A minimum series of translational and rotational motions have to be performed to dock with Athena's central part in the least time possible, since each time that a motor is ignited to perform a specific motion; $\alpha$ Centauri's fuel supply is reduced proportionally to the amount of time that the motor is turned on.

The challenge starts when Alpha Centauri is launched from Earth on course for the Athena station. Alpha Centauri has a relative velocity while approaching Athena, therefore the spaceship must first stop within a certain distance of Athena's rotational axis by turning on the front engines. In this part of the challenge, linear motion and constant deceleration is assumed. Secondly, Alpha Centauri must align its longitudinal axis with Athena's rotational axis by applying its upper and lower engines. Thirdly, Alpha Centauri must match Athena's rotational velocity by applying its lateral engines. Finally, Alpha Centauri enters into Athena's docking bay by moving slowly along its rotational axis.

The exploration variables are the spaceship's mass and rotational inertia, which are relative to its longitudinal, zenithal and azimuthal axes. The longitudinal axis is defined as the axis along the spaceship length. The zenithal axis is perpendicular to the spaceship plane and parallel to Athena's rotation axis. The azimuthal axis is parallel to 
Figure 7. Cognitive student model of PlayPhysics'first challenge

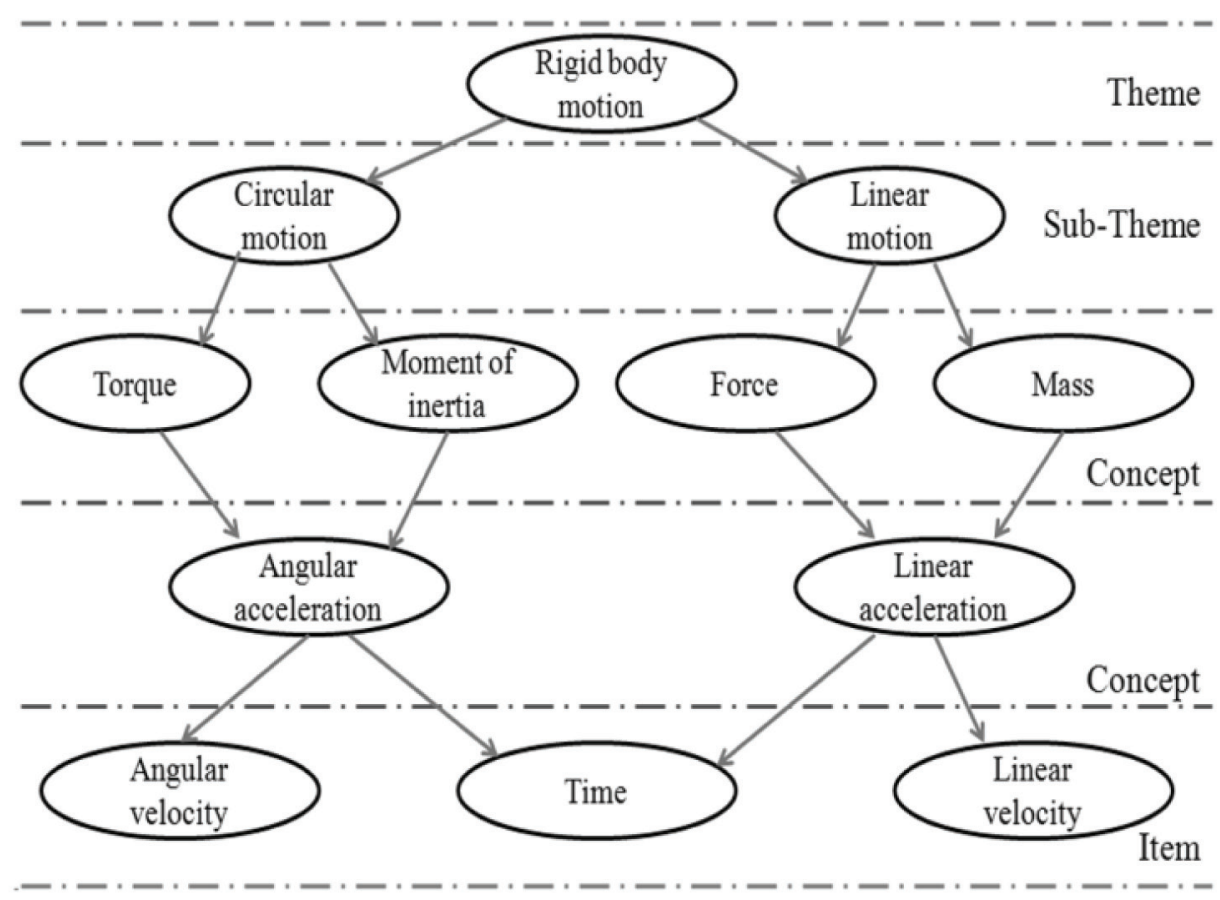

Figure 8. PlayPhysics First Challenge GUI (left) and player-character (right)
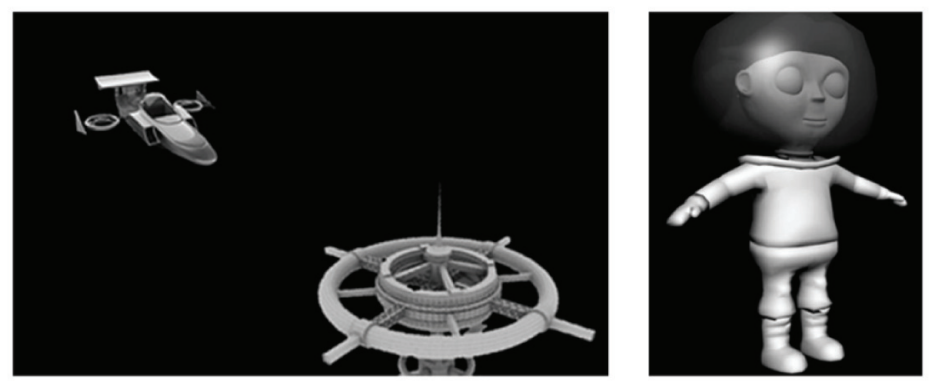

the spaceship's wings. In addition, to calculate the angular accelerations and decelerations, the forces and torques of the spaceship's motors can be explored. To recognize the learner's knowledge of this domain, the cognitive student model in Figure 7 was derived.

PlayPhysics' multimodal output adaptation will be determined by the chosen pedagogical actions. The research by Stone \& Lester (1996) will be employed as a basis for sequencing and synchronizing diverse, encouraging and praising behaviors of non-player characters. Sounds and visuals will be applied to create a feeling of immersion, create narrative progression and set an emotional state. Colors will be employed to emphasize or influence an emotional state. As a result, colors were mapped to the emotions defined by Pekrun et al. (2007) using as a basis the work of Kaya et al. (2004). If the emotion is favorable for learning, the color corresponding to this emotion will be displayed on the player-character's suit. Otherwise a color corresponding to the opposite 
emotion will be displayed on it. In Figure 8, the player-character's suit is white, which signifies no-emotion.

PlayPhysics' teaching effectiveness will be evaluated by separating students enrolled in introductory Physics courses into control and experimental groups. Both groups will perform a pre-test to determine their knowledge and understanding on Physics topics before receiving the corresponding teaching. The experimental group will interact with PlayPhysics after receiving the corresponding lectures. At the end both groups will do a post-test. The learning gains will be compared and the learning efficiency will be calculated. The latter is obtained through the quotient of the times that the student succeeded in the challenge and the total time that the student played.

\section{RESULTS AND DISCUSSION}

Seven participants, postgraduate students studying at Ph.D. level, answered a pre-test, which comprised 5 questions related to the topics in PlayPhysics' first challenge. After completing the pre-test and being made aware of their results, they answered the game dialogue questions according to their attitudes, beliefs and previous performance experience. The participants also reported the outcome-prospective emotion that they felt before starting the first challenge. The acquired evidence of the pre-test and of the answers to the game-dialogue was propagated in the outcomeprospective emotions DBN. Results, reported in Table 2 and Table 3 and the graph in Figure 9, show that in this test the affective student model had an accuracy of $57.14 \%$, i.e. out of 7 attempts the emotion was accurately inferred four times.

The nature of these results may be due to the probabilities set in the Conditional Probability Tables (CPTs) using common sense, and due to the small population of participants, since to validate the AchievementEmotions Questionnaire (AEQ), Pekrun et al. (2005) employed 389 stu-
Table 2. Mapping between numbers and outcomeprospective emotions

\begin{tabular}{|l|c|}
\hline Number & Emotion \\
\hline $\mathbf{1}$ & Anticipatory relief \\
\hline $\mathbf{2}$ & Anxiety \\
\hline $\mathbf{3}$ & Hopelessness \\
\hline $\mathbf{4}$ & Hope \\
\hline $\mathbf{5}$ & Anticipatory joy \\
\hline $\mathbf{6}$ & No emotion \\
\hline
\end{tabular}

dents. In addition, the main aim of this preliminary test was to identify deficiencies in the prototyping materials. Some postgraduate students reported that the pre-test contained Physics definitions as formulae and they did not know what the variables in the formulae meant and suggested that an explanation of the terms would make it easier to reason about them. Other postgraduate students reported that the pre-test would be easier to reason about if a diagram was included to support the question. In questions related to the game dialogue, it was signalled that the option 'no-emotion' must be added to the set of emotions that the student can report. Also, it was noticed that some student's did not know how to report the emotion they were feeling, e.g. one student reported that he felt anxious, but not in a negative way. On the other hand, in two out of three specific cases where the students reported 'anxiety' instead of 'anticipa-

Table 3. Emotion reported by the student vs. emotion predicted by the system

\begin{tabular}{|c|c|c|}
\hline $\begin{array}{c}\text { Number of } \\
\text { student }\end{array}$ & $\begin{array}{c}\text { Emotion reported by } \\
\text { the student }\end{array}$ & $\begin{array}{c}\text { Emotion predicted } \\
\text { by the system }\end{array}$ \\
\hline $\mathbf{1}$ & $\mathbf{2}$ & $\mathbf{2}$ \\
\hline $\mathbf{2}$ & $\mathbf{5}$ & $\mathbf{5}$ \\
\hline $\mathbf{3}$ & 2 & 5 \\
\hline $\mathbf{4}$ & 2 & 5 \\
\hline $\mathbf{5}$ & 2 & 5 \\
\hline $\mathbf{6}$ & $\mathbf{4}$ & $\mathbf{4}$ \\
\hline $\mathbf{7}$ & $\mathbf{5}$ & $\mathbf{5}$ \\
\hline
\end{tabular}


Figure 9. Comparison between predicted emotion and reported emotion

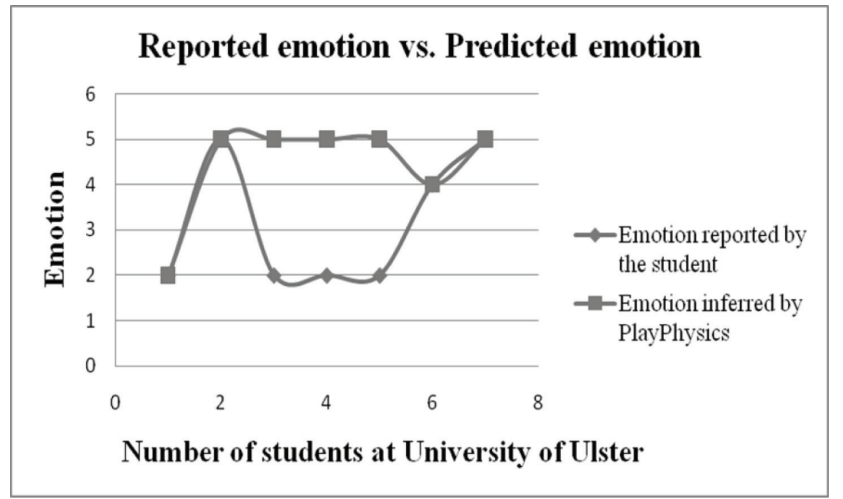

tory joy', the students obtained a mark corresponding to a high level of performance. However, the students may report 'anxiety' due to the way that the evaluation process was carried out, since they were located in the same room at the same time, they may have thought that their performance would be available to everyone. Therefore, in successive evaluations, the students will be evaluated in isolation in the Gesell dome.

\section{CONCLUSION AND FUTURE RESEARCH DIRECTIONS}

Intelligent game-based learning environments or educational games are inherently effective motivational tools. However, attaining the learner's attention and engagement is simply not enough. Educational games have yet to prove effective at teaching and must incorporate assessment mechanisms and suitable feedback to support independent learning. Incorporating Intelligent Tutoring Systems (ITSs) into educational games is a plausible solution to these problems, since ITSs can keep track of each student's history of interaction and adapt accordingly to the identified student needs. The advantages of Affective Gaming, such as evaluating the player's experience and understanding when an emotion is relevant, were emphasized. Our research focuses on en- hancing ITSs and intelligent game-based learning environments through building an affective student model. This model infers emotion from cognitive and motivational variables using the learner's observable behavior and employing the control-value theory of achievement emotions. A Probabilistic Relational Models (PRMs) approach to building the innovative affective student model was discussed. PRMs facilitate the design process of Bayesian Networks (BNs), since they reduce the required complexity. A preliminary evaluation was carried out with seven participants to identify deficiencies in the prototyping material. An accuracy of $57.14 \%$ was achieved when the reported-emotion by the students was compared with the predicted emotion by the system. These results may be influenced by the probabilities set in the Conditional Probability Tables (CPTs). To model accurately the CPTs and evaluate effectively the model a larger population of participants would be necessary. Students signaled some recommendations to enhance the effectiveness of the prototyping material, which will be taken into account when performing future evaluations.

Future work includes testing the accuracy of the affective student model through a prototyping exercise involving a large number of undergraduate students enrolled in an introductory Physics course. The objective is to determine if the identified variables can ensure the accurate inferring 
of the learner's emotions. Once the affective student model can infer accurately the learner's emotional state, it will be incorporated into the Olympia architecture and PlayPhysics application. The tutor model selects and implements the appropriate response that maximizes learning or motivation. PlayPhysics will be evaluated through the comparison of learning gains and the calculation of learning efficiencies. Research focused on the communication modules of ITSs, related to conveying a response that enables the student to understand the effect of his or her actions, is gaining popularity and promises to significantly enhance the teaching-learning experience.

\section{ACKNOWLEDGMENT}

We want to express our gratitude to Richard Walsh, from ZooCreative, for modeling the 3D player-characters of PlayPhysics. We also want to recognize the suggestions and direction provided by Prof. Mark Shevlin, from the Psychology Research Institute, and Dr. Lee Cadieux, from the Art and Design Research Institute, at the University of Ulster, Magee.

\section{REFERENCES}

Ajzen, I. (2005). Attitudes, Personality and Behaviour ( $2^{\text {nd }}$ ed.). Maidenhead, Berkshire: Open University Press.

Alsmeyer, M., Luckin, R., \& Good, J. (2008). Developing a novel interface for capturing selfreports of affect. In Proceedings of the CHI'08: Conference on Human Factors in Computing Systems (pp. 2883-2888). Florence, Italy: ACM Press.
Barnett, M., Squire, K., Grant, J., \& Higginbotham, T.(2004). Electromagnetism supercharged!: Learning Physics with Digital Simulation Games. In Y.Kafai, W.A. Sandoval, N. Enyedi,A.S. Nixon $\&$ F. Herrera (Eds.), Proceedings of the $6^{\text {th }}$ International Conference on Learning Science (pp. 513-520). Mahwah, NJ: International Society of the Learning Sciences.

Bates, J., Loyall, A., \& Reilly, W. (1992). Integrating reactivity, goals and emotion in a broad agent. CiteSeerX. Retrieved March 8, 2010, from http:// www.cs.cmu.edu/afs/cs/project/oz/web/papers/ CMU-CS-92-142.ps.gz

Bergeron, B. (2006). Developing Serious Games. Massachusetts: Charles River Media, Inc.

Brezinka, V., \& Hovestadt, L. (2007). Serious Games Can Support Psychotherapy of Children and Adolescents. In HCI and Usability for Medicine and Health Care (pp. 357-364). Heidelberg: Springer Berlin. doi:10.1007/978-3-540-768050_30

Bunt, A., \& Conati, C. (2003). Probabilistic Student Modeling to Improve Exploratory Behavior. Journal of User Modeling and User-Adapted Interaction, 13(3), 269-309. doi:10.1023/A:1024733008280

Burleson, W., \& Picard, R. W. (2007). Evidence for Gender Specific Approaches to the Development of Emotionally Intelligent Learning Companions. IEEE Intelligent Systems, 22(4), 62-69. doi:10.1109/MIS.2007.69

Carpenter, A., \& Windsor, H. (2006). A head of the game?- Games in Education. Serious Games Source. Retrieved January 24, 2010, from http://seriousgamessource.com/features/ feature_061306_ahead_of_the_game.php 
Cassell, J., Högni Vilhjálmsson, H., \& Bickmore, T. (2001). BEAT: The Behaviour Expression Animation Toolkit. In L. Pocock (Ed.), Proceedings of the 28th annual conference on Computer graphics and interactivetechniques (pp. 477-486). Los Angeles, CA: ACM Press.

Chalfoun, P., Chaffar, S., \& Frasson, C. (2006, June). Predicting the Emotional Reaction of the Learner with a Machine Learning Technique. Paperpresented at the Workshop on Motivational and Affective Issues in the International Conference on Intelligent Tutoring Systems, Jhongli, Taiwan. Retrieved January 25, 2010, from http://wwwetud.iro.umontreal.ca/ chaffars/Papers/ITS $\% 20$ Workshop\%202006\%20-\%20Chalfoun\%20ChaffarFrasson $\% 20-\% 20$ FINAL.pdf

Chumbley, J., \& Griffiths, M. (2006). Affect and the Computer Game Player: The Effect of Gender, Personality, and the Game Reinforcement Structure on Affective Responses to Computer Game-Play. CyberPsychology \& Behaviour, 9(3), 308-316. doi:10.1089/cpb.2006.9.308

Clancey, W. J., \& Buchanan, B. (1982). Exploration of teaching and problem solving strategies '1979-1982'. Unpublished manuscript, Stanford University, Stanford, California.

Collins, K. (2008). Game sound: an introduction to the history, theory and practice of video game music and sound design. Cambridge, MA: MIT Press.

Conati, C., \& Maclaren, H. (2009). Empirically Building and Evaluating a Probabilistic Model of User Affect. User Modeling and User-Adapted Interaction, 19(3), 267-303. doi:10.1007/s11257009-9062-8

D’Mello, S. K., Craig, S.D., Witherspoon, A., McDaniel, B.T., \& Graesser, A.C. (2008). Automatic Detection ofLearner'sAffect from Conversational Cues. User modelling and User-Adapted interaction, 8(1-2), 45-80.
Del Soldato, T., \& Du Boulay, B. (1995). Implementation of motivational tactics in tutoring systems. Journal of Artificial Intelligence in Education, 6(4), 337-378.

Dias, J., Paiva, A., \& Vala, M. Aylett, R., Woods, S., Zoll, C., \& Hall, L. (2006). Empathic characters in computer-based personal and social education. In M.Pivec (Ed.), Affective and Emotional Aspects of Human-Computer Interaction (pp. 246-254). Netherlands, Amsterdam: IOS Press.

Du Boulay, B., \& Luckin, R. (2001). Modelling human teaching tactics and strategies for tutoring systems. International Journal of Artificial Intelligence in Education, 12, 235-256.

Ekman, P., \& Friesen, W. V.(1978). Facial Action Coding System: A Technique for the Measurement of Facial Movement. Palo Alto, CA: Consulting Psychologists Press.

Francis, J. J., Eccles, M. P., Johnston, M., Walker, A., Grimshaw, J., Foy, R., et al. (2004). Constructing Questionnaires based on the Theory of Planned Behaviour: A manual for Health Services Researchers. Unpublished manuscript, University of Newcastle, Newcastle, UK.

Goetz, T., Frenzel, A. C., Pekrun, R., Hall, N. C., \& Lüdtke, O. (2007). Between- and within- domain relations of student's academic emotions. Educational Psychology, 99(11), 715-733.

Höök, K. (2005). User-Centred Design and Evaluation of Affective Interfaces. In Ruttkoy, Z., \& Pelachaud, C. (Eds.), From Brows to Trust: Evaluating Embodied Conversational Agents (pp. 127-160). Netherlands: Springer.

Jaques, P. A., \& Vicari, R. M. (2007). A BDI Approach to Infer Student's Emotions in an Intelligent Learning Environment. Journal of Computers \& Education, 49(2), 360-384. doi:10.1016/j. compedu.2005.09.002 
Jensen, F. V., \& Nielsen, T. D. (2007). Bayesian Networks and Decision Graphs ( $2^{\text {nd }}$ ed.). New York, NY: Springer Science + Business Media, LLC.

Johnson, W. L., Rickel, J. W., \& Lester, J. C. (2000). Animated pedagogical agents: face to face interaction in interactive learning environments. International Journal of Artificial Intelligence in Education, 11(1), 47-78.

Kaya, N., Epps, H. H., \& Hall, D. (2004). Relationship between color and emotion: a study of college students. College Student Journal, 396-405.

Keller, J. M.(2006). What is motivational design? Unpublished manuscript, Florida State University, Tallahassee, Florida.

Lepper, M. R., Woolverton, M., \& Mumme, D. L. (1993). Motivational Techniques of ExpertHuman Tutors: Lessons for the Design of Computer Based Tutors. In Lajoie, S. P., \& Derry, S. J. (Eds.), Computers as Cognitive Tools (pp. 75-105). Mahwah, NJ: Lawrence Erlbaum Associates.

Lester, J. C., Voerman, J. L., Towns, S. G., \& Callaway, C. B. (1999). Diectic believability: Coordinating gesture, locomotion and speech in life-like pedagogical agents. Applied Artificial Intelligence, 13, 383-414. doi:10.1080/088395199117324

Malone, T. W.(1981). Toward a Theory of Intrinsically Motivating Instruction. Cognitive Science, 5(4),333-369. doi:10.1207/s15516709cog0504_2

Malone, T. W., \& Lepper, M. R. (1987). Making Learning Fun: A Taxonomy of Intrinsic Motivations for Learning. In Snow, R. E., \& Farr, M. J. (Eds.), Aptitude, Learning and Instruction III: Conative and Affective Process Analyses (pp. 223-253). Hillsdale, N.J: Erlbaum.

Mateas, M. (1997). An Oz-Centric Review of Interactive Drama and Believable Agents. Unpublished manuscript. School of Computer Science, Carnegie Mellon University.
McQuiggan, S. W., Mott, B. W., \& Lester, J. C. (2008). Modeling Self-efficacy in Intelligent Tutoring Systems: An inductive approach. User Modeling and User-Adapted Interaction, 18, 81-123. doi:10.1007/s11257-007-9040-y

Muñoz, K., Noguez, J., Mc Kevitt, P., Neri, L., Robledo-Rella, V., \& Lunney, T. (2009). Adding Features of Educational Games for Teaching Physics [Electronic version]. In Proceeedings of the 39th IEEE International Conference Frontiers in Education (pp. M2E-1-M2E-6). Retrieved January 25, 2010, from http://ieeexplore.ieee.org/ stamp/stamp.jsp?tp=\&arnumber $=5350630 \& i s n u$ mber $=5350396$

Nijdam, N. A. (2005). Mapping emotion to color. Retrieved April 15, 2010, from http://hmi.ewi. utwente.nl/verslagen/capita-selecta/CS-NijdamNiels.pdf

Noguez, J., \& Sucar, E. (2005). A Semi-open Learning Environment for Virtual Laboratories. In $4^{\text {th }}$ Mexican International Conference on Artificial Intelligence, Advances in Artificial Intelligence (pp. 1185-1194). Heidelberg: Springer Berlin.

Noguez, J., \& Sucar, L. (2006). Intelligent Virtual Laboratory and Project Oriented Learning for Teaching Mobile Robotics. International Journal of Engineering Education, 22(4), 743-757.

Oblinger, D. G. (2004). The Next Generation of Educational Engagement [Electronic version]. Journal of interactive media in education, 8. Retrieved November 30, 2009, from http://wwwjime.open.ac.uk/2004/8/

Ortony, A., Clore, G. L., \& Collins, A. (1990). The Cognitive Structure of Emotions. New York: Cambridge University Press.

Pekrun, R. (2005). Progress on open problems in educational emotion research. Learning and Instruction, 15(5), 497-506. doi:10.1016/j.learninstruc.2005.07.014 
Pekrun, R. (2006). The control-value theory of achievement emotions: assumptions, corollaries, and implications for educational research and practice. Educational Psychology Review, 18(4), 315-341. doi:10.1007/s10648-006-9029-9

Pekrun, R., Frenzel, A. C., Goetz, T., \& Perry, R. P. (2007). The Control Value Theory of Achievement Emotions. An integrative Approach to Emotions in Education. In Shutz, P. A., \& Pekrun, R. (Eds.), Emotion in Education (pp. 13-36). London: Elsevier. doi:10.1016/B978-012372545-5/50003-4

Pekrun, R., Goetz, T., \& Perry, R. P. (2005). Achievement Emotions Questionnaire (AEQ). User's manual. Unpublished manuscript, University of Munich, Munich.

Picard, R. W., Papert, S., Bender, W., Blumberg, B., Breazeal, C., \& Cavallo, D. (2004). Affective learning -A Manifesto. BT Technology Journal, 22(4), 253-269. doi:10.1023/ B:BTTJ.0000047603.37042.33

Razek, M. A., Chaffar, S., Frasson, C., \& Ochs, M. (2006). Using machine learning techniques to recognize emotions for online learning environments. In Pivec, M.(Ed.), Affective and Emotional Aspects of Human-Computer Interaction (pp. 255-265). Amsterdam, Netherlands: IOS Press.

Rebolledo-Mendez, G., Du Boulay, B., \& Luckin, R. (2006). Motivating the Learner: An Empirical Evaluation. In M. Ikeda, K. Ashley \& T.W. Chan (Eds.), The $8^{\text {th }}$ Intelligent Tutoring Systems International Conference (pp. 545-554). Heidelberg: Springer Berlin.

Schaller, D. (2005, June). What Makes a Learning Game? Paper presented at the Web Designs for Interactive Learning Conference, Ithaca, NY. Retrieved January 22, 2010, from http://www. eduweb.com/schaller-games.pdf
Squire, K. (2003). Video Games in Education. International Journal of Intelligent Simulations and Gaming, 2(1), 49-62.

Stone, B. A., \& Lester, J. C. (1996). Dynamically sequencing an animated pedagogical agent. In Proceedings of the $13^{\text {th }}$ National Conference on Artificial Intelligence (pp. 424-431). Portland, Oregon: The MIT Press.

Sucar, L. E., \& Noguez, J. (2008). Student Modeling. In Pourret, O., Naïm, P., \& Marcot, B. (Eds.), Bayesian Networks: A Practical Guide to Applications (pp. 173-185). West Sussex, England: J. Wiley \& Sons.

Sykes, J. (2006). Affective Gaming: Advancing the Argument for Game-Based Learning. In Pivec, M. (Ed.), Affective and Emotional Aspects of Human-Computer Interaction (pp. 3-7). Amsterdam, Netherlands: IOS Press.

Zammitto, V. I. (2005, June). The Expression of Colours. Paper presented at the International Conference Changing Views: Worlds in Play, Vancouver, CA. Retrieved January 24, 2010, from http://www.digra.org/dl/db/06278.05074.pdf

\section{ADDITIONAL READING}

Pivec, M. (2006). Affective and emotional aspects of human-computer interaction. Amsterdam, Netherlands: IOS Press.

Pourret, O., Naïm, P., \& Marcot, B. (2008). Bayesian Networks: A Practical Guide to Applications. West Sussex, England: J. Wiley \& Sons.

Squire, K. (2006). From Content to Context: Video Games as Designed Experience. Educational Researcher, 35(8), 19-29. doi:10.3102/0013189X035008019 
Squire, K., Jenkins, H., Holland, W., Miller, H., O'Driscoll, A., Tan, K. P., \& Todd, K. (2003). Design Principles of Next Generation Digital Gaming for Education. Educational Technology, 43(5), 17-23.
Woolf, B. P. (2009). Building Intelligent Interactive Tutors: Student-centered strategies for revolutionizing e-learning. Burlington, NJ: Elsevier, Inc. 